\title{
EL RESARCIMIENTO A LAS ENTIDADES PÚBLICAS CONTRATANTES EN EL MARCO DE LAS GARANTÍAS QUE AMPARAN LA CALIDAD
}

\section{Sandra Patricia Sotelo Rojas ${ }^{1}$}

Recibido: 30 de abril de 2013

Revisado: 12 de junio de 2013

Aprobado: 18 de junio de 2013

\section{Resumen}

En el presente artículo de investigación se analiza porqué al hacerse efectivas las pólizas de seguro por el cumplimiento defectuoso del objeto contractual no es posible resarcir en forma inmediata y directa a las entidades sometidas al Estatuto General de Contratación de la Administración Pública (E.G.C.A.P.)², situación que, en Colombia, tiene su génesis en el marco presupuestal y se agrava en el contexto legislativo y reglamentario de los mecanismos de cobertura del riesgo. Para ello se analizará la figura indemnizatoria en los seguros de daños y cómo sus características no han pasado normativamente al derecho público en las mismas condiciones del derecho privado, determinando la posible causa que no permite la realización del derecho al resarcimiento cuando se hacen efectivas estas garantías contractuales; finalizando con algunas consideraciones que evidencian que éstas, en general, están instituidas más en favor del Estado que de las entidades con capacidad para celebrar contratos, individualmente consideradas.

\footnotetext{
${ }^{1}$ Abogada de la Universidad Libre, Especialista en Docencia Universitaria - Universidad Militar Nueva Granada. Correo Electrónico: ssotelor@yahoo.es

${ }^{2}$ Ley 80 de 19983, Ley 1150 de 2007, y Decreto Reglamentario 734 de 2012.
} 
Palabras clave: Daño, garantías, siniestro, resarcimiento.

\title{
REDRESS THE CONTRACTING PUBLIC AGENCIES UNDER THE QUALITY GUARANTEES OF
}

\begin{abstract}
This article discusses why research to be effective insurance guarantees for defective performance of the contractual object is not possible to compensate immediately and directly to the entities subject to General Contracting Public Administration, situation that in Colombia, has its genesis in the budgetary framework and is worse in the legislative and regulatory mechanisms hedging. This figure will be discussed in insurance compensatory damages and how their characteristics have not been normatively public law under the same conditions of private law, determining the possible cause that does not allow the realization of the right to compensation when these guarantees are effective contract, ending with some evidence that those considerations generally are instituted for the State more than for entities with capacity to contract, taken individually.
\end{abstract}

\section{Key Words}

Damage, guarantees, claim, compensation.

\section{REPARAÇÃO A CONTRATAÇÃO AS AGÊNCIAS PÚBLICAS NO QUADRO DO GARANTIAS QUE PROTEGEM A QUALIDADE.}




\section{Resumo}

Este artigo discute por que a pesquisa a ser apólices de seguro eficazes para o cumprimento defeituoso do objeto contratual não é imediatamente possível compensar sujeito direta e entidades contratantes Geral da Administração Pública (EGCAP), situação que, na Colômbia, tem a sua génese no âmbito do orçamento e é exacerbada no contexto legislativo e regulamentar mecanismos de hedge. Este valor será discutido em seguro de responsabilidade civil por danos e como suas características não foram normativamente direito público sob as mesmas condições de direito privado, determinando a possível causa que não permite a realização do direito a indemnização quando essas garantias são eficazes contrato, que termina com algumas considerações que indicam que eles geralmente são instituídos para o Estado mais do que para as entidades com capacidade para contrair individualmente considerado.

Palavras-chave: Damage, garantias, reclamação, indenização-

\section{Introducción}

La ejecución imperfecta del objeto contractual por parte del contratista no solo lesiona a la entidad pública sino que imposibilita la satisfacción de la necesidad que la llevó a contratar; en tal virtud, el E.G.C.A.P. ha dotado a las entidades estatales de facultades como la de adelantar las gestiones necesarias para el reconocimiento y cobro de las garantías constituidas en su favor para amparar los riesgos derivados de la actividad contractual; sin embargo, en la práctica, el pago de la indemnización por parte del contratista o su garante, no genera el resarcimiento directo e inmediato del daño sufrido por la entidad, tal como sí 
ocurre en los seguros de daños regulados por el Código de Comercio cuando el asegurador efectúa el pago al beneficiario hasta por el valor asegurado.

Por lo anterior, a través del presente artículo pretende resolverse el problema de porqué al hacerse efectiva la garantía constituida a través de póliza de seguro no es posible resarcir en forma inmediata y directa a la entidad que declaró el siniestro, lo cual resulta relevante en la medida en que esa debería ser la finalidad intrínseca de las garantías, especialmente, la de las pólizas, que son los mecanismos de cobertura del riesgo más utilizados en Colombia por los contratistas.

Para tal efecto se presenta una investigación cualitativa en donde se analiza la figura indemnizatoria en los seguros de daños en comparación con la reparación derivada de la ejecución de las garantías consistentes en póliza de seguro, se analizan las normas presupuestales que rigen el ingreso de los recursos derivados del pago de las garantías así como su jurisprudencia, y se revisa el derecho chileno así como los demás mecanismos de cobertura del riesgo, determinando la causa por la cual no opera el fenómeno del resarcimiento directo e inmediato para la entidad cuando hace efectiva la garantía contractual por la ejecución defectuosa del objeto contractual.

\section{El deber de reparación en contraste con la efectividad de la póliza de calidad en los contratos estatales}

Una de las máximas romanas fue la de no causar daño a nadie "alterum non laedere" (Ulpiano), la cual tenía un fin resarcitorio, pues, a través de ella se pretendía la reparación del daño causado o restablecimiento del derecho lesionado. Esta máxima es fundamental en el derecho de daños, porque origina la 
obligación de reparar los daños causados en tanto ello sea posible, o la de resarcir de la víctima mediante una indemnización de perjuicios. En el marco de la contratación estatal, la infracción de una obligación contractual conlleva la responsabilidad del infractor (responsabilidad contractual) y en tal virtud, éste debe reparar el daño injustamente causado al otro contratante.

La finalidad del contrato es producir los efectos queridos por los contratantes (Solarte, 2011) y su principal efecto es la fuerza obligatoria, que impone un cumplimiento estricto y de buena $\mathrm{fe}^{3}$, así como un actuar recto y leal en todas las etapas del contrato (Messineo, 2007; Rivera, 1997; Stiglitz, 1998), condiciones especialmente relevantes en materia pública, pues, los contratos administrativos son los medios a través de los cuales se cumplen los fines del Estado y se solucionan las necesidades de la comunidad (Güechá, 2010; Salguero, 1983), en tal virtud no solo deben ser producto de una adecuada planeación (Escobar, 2003) sino que su correcta ejecución es de interés general y las entidades deben exigirla en forma íntegra, efectiva y oportuna ${ }^{4}$.

Pero en la ejecución del contracto subyace la posibilidad de su incumplimiento ya sea por razones atribuibles al contratista o por situaciones ajenas a los contratantes (Mantilla \& Ternera, 2007), y cuando el mismo resulta atribuible al contratista, la entidad debe iniciar las acciones necesarias para lograr la respectiva indemnización (Campillo, 2006), finalidad en la cual las garantías cumplen un papel importante como quiera que, teóricamente, los contratistas deben constituirlas para salvaguardar la integridad del patrimonio de la entidad en cuanto ellas materializan un interés económico legítimo consistente en que si se realiza el

\footnotetext{
${ }^{3}$ Para Estigarribia, la buena fe es el tema medular de la ética contractual (2011).

${ }^{4}$ CE, Sec. III, 23 de abril de 2008, expediente No. 16.491.
} 
riesgo ${ }^{5}$, subsista la tranquilidad de que se pueda conservar o reponer el objeto asegurado por parte del garante, quien, por virtud del contrato de seguro, asume el riesgo de resarcir el daño en dinero o en especie ${ }^{6}$ (Díaz, 2009; Traviesas, 1934), siempre que éste se produzca durante la vigencia del seguro (Stiglitz, 2010), toda vez el daño cubierto por él resulta de todo ataque dirigido por un tercero en contra de su afianzado (Hemard, 1925).

La materialización de la figura de la responsabilidad, que constituye una obligación resarcitoria (Mazeaud \& Tunc, 1977), supone la relación de dos sujetos en donde uno causa un daño al otro y la consecuencia jurídica es la obligación de reparar el perjuicio causado (Valencia \& Ortiz, 2002). En materia contractual, el daño, es decir, el deterioro o menoscabo (Instituto de Investigaciones Jurídicas, 1998), puede resultar de la inejecución, de la ejecución imperfecta o de la ejecución tardía $^{7}$ de la obligación (Oliveros, 2012). Sin embargo, para el presente artículo solo se considerará la ejecución imperfecta o defectuosa, que se da cuando se recibe una prestación pero ésta no se ajusta a lo pactado (Uribe, 1982), debido a que el fenómeno del resarcimiento a la entidad se analizará únicamente en el marco de los daños cubiertos por los amparos de calidad (predicable de los bienes y servicios) y estabilidad de la obra.

\footnotetext{
${ }^{5}$ En los seguros de daños regulados por el Código de Comercio, una vez acaecido el siniestro amparado, el asegurado/beneficiario adelanta el respectivo reclamo ante el asegurador, quien al constatar la producción efectiva del daño y su cuantificación, paga directamente beneficiario el valor de la pérdida como forma de resarcimiento por el daño sufrido.

${ }^{6}$ De conformidad con el artículo 1110 del Código de Comercio, la indemnización puede pagarse en dinero, o mediante la reposición, reparación o reconstrucción de la cosa asegurada, a opción del asegurador, lo cual depende de la naturaleza del objeto contractual, pues, en muchos casos, el mismo no coincide con el objeto de las aseguradoras. Sin embargo, cuando el asegurador decide indemnizar en especie, asume la posición de contratista.

${ }^{7}$ Los contratos administrativos son negocios pactados a plazo y, a diferencia de los contratos privados, no se requiere la constitución en mora del contratista, pues, ésta se configura por el vencimiento del plazo contractual sin que éste haya ejecutado sus prestaciones (Expósito, 2008; Escobar, 1993).
} 
Según Josserand, las obligaciones se ejecutan en especie y el acreedor puede exigir al deudor la prestación misma (1984), garantía del derecho de obligaciones en donde el contratista pudiera verse constreñido judicialmente a cumplir la prestación o a satisfacer su equivalente en dinero y, además, a resarcir los daños que cause si incumple (Hinestrosa, 2003); pero en el ámbito público, además de este derecho, la entidad también ostenta poderes de dirección y control de la ejecución del contrato y la ley la autoriza para exigir el cumplimiento del objeto, incluso, a través de mecanismos de intervención o coerción, entre ellos la garantía, encaminados a que el contratista cumpla sus obligaciones evitando con ello la paralización del contrato, su afectación grave o su incumplimiento (García \& Fernández, 1993; Solano, 2010).

Frente al fundamento y objetivos de la garantía contractual, la Corte Constitucional, en Sentencia C-154 de 1996, señaló que la garantía es un instrumento cuyo fin es asegurar el cumplimiento de las obligaciones de los contratistas, incluso, a través de su garante, quien debe tener la solvencia suficiente para asumir el cumplimiento del objeto contractual a través de su ejecución en especie o por medio de su ejecución en equivalente. Posteriormente, en Sentencia C-648 de 2002, esta Corporación agregó que las garantías aseguran la ejecución del contrato mediante un procedimiento extrajudicial ágil en el cual el contratista o su garante reconocen los perjuicios causados a la entidad estatal por el incumplimiento del contratista.

Si bien, el daño es capaz de producir un detrimento patrimonial debido, precisamente, a su influjo (Caballero, 1992), a través de la garantía única se busca evitar esta situación en la medida en que la contraprestación del asegurador se manifiesta en la indemnización (Chartered Insurance Institute de Londres, 1979). 
Pero para que el daño sea resarcible debe ser cierto, directo, personal y debe lesionar un interés legítimo (Bustamante, 1993; Isaza, 2009), en otras palabras, solo se puede pretender la reparación del daño propio (Orgaz, 1960), y su reparación debe ser proporcional al daño, pues, el daño indemnizado por encima del perjuicio real enriquece sin causa a la víctima, y si se indemniza por debajo la empobrece sin causa (Henao, 1998). Así, si el contratista pretendiera verse resarcido a través de la declaratoria de responsabilidad de la entidad por incumplimiento contractual, bastaría con demostrar al juez del contrato una actuación de la Administración, un daño antijurídico y la correspondiente relación de causalidad para que surgiera en cabeza de ésta el deber legal de indemnizarlo (Parra, 2003); en tal caso, la reparación sería directa, pues, no sería comprensible una sentencia favorable al contratista en la que el desembolso del pago ingresara a un patrimonio diferente del suyo.

Pero esas condiciones de resarcimiento no se dan cuando las entidades del nivel central y los establecimientos públicos son los lesionados con ocasión de una relación contractual, porque cuando surge la obligación resarcitoria como consecuencia del cobro de las garantías, el pago debe depositarse a nombre de la Dirección de Crédito Público y Tesoro Nacional del Ministerio de Hacienda y Crédito Público (en adelante DTN), porque en estos casos la entidad lesionada en su esfera patrimonial no se considerara como una persona diferente del Estado ${ }^{8}$ a pesar de que el E.G.C.A.P. sí le otorga capacidad contractual.

La entidad que exige a su contratista la constitución de un mecanismo de cobertura del riesgo adopta una medida de protección para compensar las

${ }^{8}$ El Estado es un "Conglomerado humano, social, política y jurídicamente constituido, asentado sobre un territorio determinado, sometido a una autoridad que se ejerce a través de sus propios órganos y cuya soberanía es reconocida por otros estados" (Naranjo, 1997, p. 87). 
pérdidas que le causaría el siniestro puesto que, en teoría, este costo resulta mínimo comparado con el beneficio de lograr que el contratista o su garante reparen el perjuicio materializado, evitando que éste se agrave; no obstante, en Colombia no se cumple el objetivo proteccionista de las garantías respecto del patrimonio y de los intereses de la entidad contratante y por el cual, éstas deberían asegurar en forma efectiva el cumplimiento de las obligaciones a cargo del contratista, especialmente, la obligación de calidad del objeto del contrato, y ello es así debido a la forma en que actualmente se encuentra regulado el pago de la indemnización, y que se explica a continuación.

Pese a que ni la Ley 80 de 1993, ni la Ley 1150 de 2007, ni sus decretos reglamentarios señalan expresamente que cuando se declara un siniestro en el amparo de calidad y se ordena hacer efectiva la garantía única, el valor debe cancelarse a la entidad que lo declaró con el propósito de salvaguardar el interés público implícito en los contratos estatales y lograr el cumplimiento de sus fines esenciales, estas normas tampoco señalan que el pago que efectúe el contratista y/o su garante deba consignarse o reintegrarse al Tesoro Nacional, en consecuencia, el E.G.C.A.P. presenta un vacío legislativo en este sentido respecto de las entidades del nivel central y de sus establecimientos públicos.

Sin embargo, es el mismo ordenamiento jurídico colombiano el que ha puesto a las entidades que padecen un daño originado en la ejecución contractual en la situación de no poder recibir en forma directa el pago de la indemnización, haciendo nugatorio su derecho al resarcimiento y aumentando con ello el costo del perjuicio debido al desgaste administrativo en que deben incurrir para hacer efectiva la garantía de calidad, pues, lo no regulado en el E.G.C.A.P. sí se 
considera señalado en el Estatuto Orgánico del Presupuesto ${ }^{9}$ (norma de superior jerarquía) y en tal virtud, la indemnización cancelada por el contratista o su garante debe ingresar al Tesoro Nacional; sin lugar a dudas, ésta es la causa de la imposibilidad de lograr el resarcimiento directo e inmediato de la entidad, la cual se desarrolla en el siguiente acápite.

\section{El principio de unidad de caja como causa que imposibilita el resarcimiento de la entidad en el marco de las garantías}

El presupuesto general de la Nación ${ }^{10}$ consolida las rentas nacionales provenientes de las entidades del nivel central, incluidos sus establecimientos públicos, para financiar los gastos de las entidades que lo conforman (Morales, 2009) dado que la economía colombiana es una economía de planificación central, lo cual implica que las decisiones económicas se deban adoptar centralizadamente y consultando las necesidades a satisfacer (Ariño, 2003), las cuales se atienden en orden de prioridades.

Las actuaciones de la Administración deben obedecer al principio de planeación porque a través de él se evita la improvisación y el gasto público se ejecuta al amparo de los principios del Estatuto Presupuestal, entre ellos, el principio de "unidad de caja" (artículo 16 del Decreto 111 de 1996), por virtud del cual: "Con el recaudo de todas las rentas y recursos de capital se atenderá el pago oportuno de las apropiaciones autorizadas en el presupuesto general de la Nación" y, "Los excedentes financieros de los establecimientos públicos del orden nacional son propiedad de la Nación...", este principio constituye la base del orden financiero

\footnotetext{
${ }^{9}$ Decreto 111 de 1996.

${ }^{10}$ A nivel nacional, el presupuesto se aprueba por ley y, a nivel departamental, distrital y municipal, se aprueba por ordenanza o acuerdo (Ocampo, 2008).
} 
del Estado a cuyo amparo se busca la gestión ordenada y eficiente de los recursos estatales a través de una cuenta única para que la asignación de recursos públicos sea conforme con las necesidades públicas y no obedezca a preferencias ni tratos discriminatorios.

Por su parte, el artículo 35 de la Ley 42 de 1993 define la Hacienda Nacional como "...el conjunto de derechos, recursos y bienes de propiedad de la Nación. Comprende el tesoro nacional y los bienes fiscales; el primero se compone del dinero, los derechos y valores que ingresan a las oficinas nacionales a cualquier título..." (Negrillas y subrayas fuera de texto).

Cabe señalarse, que la gestión económica, financiera y contable de los recursos públicos en Colombia está a cargo de la DTN, de conformidad con el artículo 103 eiusdem, que dispone que: “... los órganos del orden nacional de la administración pública sólo podrán depositar sus recursos en la cuenta única nacional que para el efecto se establezca, a nombre de la dirección del tesoro nacional..." (Subrayas fuera de texto).

A su vez, la Corte Constitucional en Sentencia No. C-478 de 1992 señaló: "El artículo 12 de la Ley 38 de 1989 consagra el principio de la unidad de caja, indispensable para un manejo unitario de los fondos públicos. Según dicha norma, los dineros que entran al tesoro público, cualquiera sea su proveniencia, se funden en una caja común, y de ella se podrán destinar a los cometidos que se determinan en el presupuesto" (negrillas y subrayas fuera de texto). Posteriormente, en sentencia C-337 de 1993, indicó que: "Sin este principio hay una desorientación del gasto público, y entonces se hace poco viable destinar el gasto hacia las áreas prioritarias. Se necesita pues, una libertad para destinar el gasto a lo más conveniente, según las circunstancias de tiempo, modo y lugar". 
Esta jurisprudencia resulta cuestionable en materia de garantías contractuales porque avala una aplicación cerrada del principio de unidad de caja que no solo desconoce la naturaleza indemnizatoria de los mecanismos de cobertura del riesgo y que en estos casos la representación del Estado está ligada a la facultad legal de celebrar contratos, sino también la legitimación de la entidad contratante para hacerlas efectivas como beneficiaria directa de ellos, facultad que resulta esencial para proteger la correcta ejecución del presupuesto que le fue asignado para contratar un objeto de interés general, y que se ve frustrada ante la obligación de someterse nuevamente al ciclo presupuestal para lograr el resarcimiento del daño acaecido a través de la asignación de nuevos recursos, con el agravante de que la gestión de recursos conlleva la posibilidad de que éstos no se aprueben, por ejemplo, porque la necesidad que originó el contrato en que se produjo el siniestro no resulte ser una prioridad del gasto público de conformidad con el respectivo plan de desarrollo o con la política fiscal de la correspondiente vigencia, finalidad protegida por el principio de unidad de caja debido a que los recursos públicos son escasos.

Así las cosas, en la práctica, cuando una entidad del nivel central o un establecimiento público declara un siniestro y el contratista o su garante honran su deber resarcitorio pagando el valor del daño, la suma de dinero debe consignarse a nombre de la DTN ${ }^{11}$, con lo cual los efectos nefastos del siniestro siguen siendo padecidos por la entidad contratante quien, por razones presupuestales y/o de planta, generalmente no está en capacidad de atender en forma inmediata sus consecuencias nocivas y por contera, debe asumir una carga adicional: la de gestionar nuevos recursos para reparar el daño, con el agravante de que la

\footnotetext{
${ }^{11}$ Si la consignación se efectúa a nombre de la entidad declaró el siniestro, ésta debe reintegrar el valor del siniestro a la DTN; y si el pago se efectúa a través de la compensación de las sumas adeudadas al contratista, la entidad debe efectuar la respectiva devolución de apropiación, pero, en todo caso, el dinero debe ingresar al Tesoro Nacional.
} 
necesidad que la llevó a contratar seguirá insatisfecha mientras le asignan presupuesto para atenderla en la forma inicialmente prevista pero a mayor costo en términos económicos y de tiempo, pues, la ejecución de la nueva partida presupuestal pasará por la obligación de adelantar un nuevo proceso de contratación.

Esta es una situación que se opone la lógica del derecho de daños, si bien la ejecución del objeto contractual alberga riesgos cuya realización puede aparejar un perjuicio patrimonial, lo que cualquier jurista supone es que la garantía de calidad constituida por el contratista asegura que, si el siniestro acontece, por este medio la entidad logrará una reparación efectiva, es decir, una reparación oportuna, directa y proporcional al daño sufrido. Pero la práctica es diferente porque la legislación colombiana indica que cuando las entidades anteriormente referidas hacen efectiva una garantía contractual, el valor del siniestro debe ser consignado a la DTN, lo cual no satisface la finalidad indemnizatoria del contrato de seguro en la medida en que, si esta Dirección no padeció directamente ese menoscabo patrimonial, lo que virtualmente se configura es la institución del enriquecimiento $\sin$ causa $^{12}$ derivada del perjuicio de la entidad contratante, menoscabo que no solo es económico sino también administrativo porque ésta es la única legitimada para adelantar el procedimiento de declaratoria del siniestro.

De conformidad con la teoría de las obligaciones, el contrato constituye un vínculo bajo unas reglas que solo afectan a los contratantes y no a terceros, pero en materia de garantías, en Colombia hay un vacío legal que conculca el principio de

\footnotetext{
${ }^{12}$ Los artículos 1088 y 1089 del Código de Comercio establecen que la indemnización derivada de los seguros de daños no pueden constituir fuente de enriquecimiento para el asegurado/beneficiario debido a su carácter indemnizatorio.
} 
relatividad de los actos o negocios jurídicos ${ }^{13}$ toda vez que por medio de los mecanismos de cobertura del riesgo no se logra una efectiva protección del interés vinculado a la obtención del objeto contractual. Es evidente que no es suficiente el deber amparar las obligaciones asumidas por el contratista si, al momento de hacer efectiva una garantía, la consecuencia no es el resarcimiento directo de la entidad contratante sino el pago a la DTN, Dirección que, aun siendo parte del Estado, no deja de ser un tercero diferente de la entidad que padeció el daño y por ello declaró el siniestro.

Esta obligación también desconoce que la representación del Estado para fines contractuales no está ligada al concepto de personería jurídica de las entidades sino al de autonomía administrativa, pues, éstas pueden celebrar contratos si la ley las autoriza para ello, regla que, incluso, es aplicable a las controversias judiciales derivadas de la actuación contractual (Herrera, 2006) de conformidad con el inciso $5^{\circ} \mathrm{del}$ artículo 159 del Código de Pro cedimiento Administrativo y de lo Contencioso Administrativo; así, si se considerara a la entidad contratante como una persona que forma parte del Estado pero que es diferente de él para efectos contractuales, resultaría forzoso concluir que tras la ocurrencia de un siniestro amparado por una garantía contractual, su patrimonio sería el afectado y, en consecuencia, el resto del Estado no podría beneficiarse por virtud de la obligación de consignación a través de la DTN, del perjuicio sufrido por una de sus entidades, pues, la lógica del derecho de daños informa que la acción indemnizatoria corresponde solo a quien sufrió el perjuicio.

El autor de un daño adquiere el deber indemnizar a quien lo padeció y esa reparación debe ser proporcional al daño, esta es una garantía del derecho de

\footnotetext{
${ }^{13}$ De conformidad con el artículo 32 de la Ley 80 , el contrato estatal se reconoce como el acto generador de obligaciones entre los contratantes.
} 
daños, pero si el perjuicio no existe, por contera tampoco nace el derecho al resarcimiento, esta lógica conlleva a la conclusión de que si la DTN no es parte del contrato estatal, no es la asegurada/beneficiaria del contrato de seguro y no es la víctima directa del daño causado por el contratista, tampoco le asiste derecho ni legitimación alguna para recibir el valor que paguen el contratista o su garante con ocasión del siniestro contractual declarado; aceptar lo contrario es impedir que la entidad contratante cumpla los fines institucionales o estatales perseguidos con el contrato celebrado, es aceptar que el objeto contractual puede pasar desapercibido, pues, si la DTN no cuenta con la titularidad de lo principal, que es el derecho al resarcimiento a través del procedimiento para hacer efectivas las garantías, tampoco posee el derecho accesorio a que se le pague el valor del siniestro declarado, sea en dinero o en especie.

No obstante, se reitera que en este tema el ordenamiento jurídico colombiano no es acorde al derecho de daños porque actualmente el valor de la indemnización originada en un siniestro declarado debe consignarse a nombre de la DTN, situación que acarrea las siguientes consecuencias:

En primer lugar, "el remedio resulta peor que la enfermedad" porque la entidad incurre en un desgaste administrativo para declarar, cuantificar y ordenar el pago del siniestro, así como para efectuar su cobro; en este proceso se ven afectados los principios de economía, celeridad y planeación porque al final no habrá un resarcimiento directo e inmediato y la entidad deberá tramitar una nueva partida presupuestal para lograr la reparación del daño a través de la celebración de un segundo contrato estatal que traerá consigo su propio desgaste administrativo.

En segundo lugar, la conclusión evidente consiste en que no vale la pena adelantar este trámite porque al final la Administración quedará con un daño sin 
reparación ni indemnización, en consecuencia, no serán pocas las ocasiones en que la entidad prefiera un mal arreglo con el contratista a una declaratoria de siniestro, con lo cual, las garantías perderán su naturaleza indemnizatoria por tornar en un procedimiento ineficaz que solo retarda la consecución del objeto contractual y que hace nugatorio el derecho de la entidad al resarcimiento.

¿Por qué sería preferible un mal arreglo con el contratista? Porque si bien, la facultad de dirección y control permite a las entidades estatales el uso de mecanismos de intervención tales como: el arreglo directo de controversias contractuales, la modificación del contrato (bilateral o unilateral), la imposición de las multas de apremio pactadas, la declaratoria de caducidad, la declaratoria de incumplimiento y el procedimiento para hacer efectivas las garantías, entre otras; cuando con ocasión del contrato se producen conflictos o divergencias, el camino más expedito para las partes consiste en establecer acuerdos para evitar controversias judiciales, pues, si bien, el obrar de la Administración es eminentemente reglado ${ }^{14}$, en materia de contratación estatal esta máxima se ve exceptuada por el principio de la autonomía de la voluntad contractual, que le permite efectuar acuerdos con el contratista para lograr el cumplimiento del objeto contractual, camino que a todas luces resulta más eficiente que el desgastante proceso de exigir al garante el pago de una indemnización que, indudablemente, deberá consignarse a la DTN.

Es cierto que la Administración puede hacer efectivas las garantías que amparan la estabilidad y calidad de la obra, la calidad del servicio y, la calidad y correcto funcionamiento de los bienes y equipos suministrados, pero este ciclo resulta ser

\footnotetext{
14 La administración es la actividad que despliega el Estado para alcanzar sus fines y se fundamenta en el principio de legalidad (Giraldo, 2010).
} 
un verdadero contrasentido: la garantía única, que debería tener una función reparadora ${ }^{15}$, en la práctica ha adquirido una función preventiva, porque cuando la entidad cita al garante, suele lograr que el contratista se comprometa a ponerse al día con sus obligaciones contractuales o a responder por la calidad de los bienes, servicios u obra contratados sin necesidad de la declaratoria de siniestro. Desafortunadamente, este resultado generalmente es más consecuencia del temor del contratista al reporte en el sector asegurador o a quedar inhabilitado para contratar con el Estado en los términos del artículo 90 del Estatuto Anticorrupción, que de su conciencia frente al deber de reparar los daños que haya podido causar a su contratante.

La discusión que se plantea no se presentaría si el legislador hubiera autorizado expresamente la posibilidad de que el pago del valor del siniestro se pudiera generar en dinero o en especie, especificando que, en el primer caso, el pago efectuado por el contratista y/o su garante debería ingresar directamente a la entidad, tal como lo hiciera el gobierno nacional, en relación con las multas, en el artículo 73 del Decreto 222 de 1983, antiguo régimen contractual, que establecía que "El valor de las multas y de la cláusula penal pecuniaria... ingresará al tesoro de la entidad contratante y podrá ser tomado directamente del saldo a favor del contratista, si lo hubiere, o de la garantía constituida...". Pero el legislador no ha definido este importante asunto y por ello el régimen de garantías de la contratación pública es contrario a la lógica del derecho de daños, a la lógica del derecho de seguros y por contera, a la lógica de la teoría general de las obligaciones, que siempre han reconocido el derecho de la víctima al resarcimiento o reparación del daño en forma oportuna, directa y suficiente.

\footnotetext{
${ }^{15}$ Los seguros tienen un carácter estrictamente indemnizatorio porque imponen al asegurador el deber de reparar la pérdida efectivamente sufrida, hasta por el valor amparado.
} 
En resumen, las sumas canceladas por los contratistas o por sus garantes como consecuencia de los siniestros declarados para hacer efectivas las garantías contractuales deben cumplir el principio de unidad de caja, y como consecuencia de ello, no pueden ser utilizados directamente por las entidades beneficiarias de las mismas, debiendo ser reintegrados al tesoro nacional, y si ellas requieren efectuar algún gasto con cargo a dichos recursos, el mismo debe ser presupuestado a través de la Dirección General del Presupuesto Público Nacional.

No obstante, este principio tiene su excepción, al respecto, la Sala de Consulta y Servicio Civil del Consejo de Estado en concepto del 15 de noviembre de 2007, No. Interno 1.852, señaló que de conformidad con el principio de unidad de caja, los recursos de la Nación van a una bolsa común para responder por los gastos decretados en el presupuesto, pero aclara que el artículo 352 de la Carta Política reconoce la existencia de presupuestos separados en el orden nacional y territorial, así como los de las entidades descentralizadas de cualquier nivel, con lo cual los entes territoriales y las entidades descentralizadas por servicios pueden administrar sus recursos dentro de los límites constitucionales y legales porque éstos no hacen unidad de caja con los de la Nación por tratarse de presupuestos y patrimonios independientes constitucional y legalmente.

Por lo anterior, es dable concluir que cuando una entidad del orden nacional (sector central y establecimientos públicos) se ve perjudicada con la ocurrencia de un siniestro amparado por la garantía de calidad del contrato, ese daño se predica del Estado y no de la entidad contratante porque, de conformidad con el artículo 1 de la Carta Política, el Estado Colombiano está organizado en forma de república unitaria y la Hacienda Nacional obedece al principio de unidad de caja. Sin embargo, además de la Hacienda Nacional hay una hacienda pública en los órdenes departamental, distrital y municipal, que a pesar de regirse por principios 
y normas comunes tiene plena autonomía para el recaudo, administración y disposición de sus haberes, este es un desarrollo de la descentralización territorial que no solo permite asignar competencias a los entes territoriales para realizarlas en nombre propio y bajo su responsabilidad (Vedel, 1980; Higuita, 2006) sino que también involucra la transferencia de recursos (Villar, Hernández, Valencia, Cotrino, Pino \& Atehortúa, 2000), de conformidad con el artículo 356 ibídem.

Así las cosas, al amparo del principio de unidad de caja (que solo rige para las entidades que integran el Presupuesto General), los recursos son recaudados y distribuidos por la Tesorería General de la Nación, mientras que las entidades descentralizadas, por el hecho de tener su propio presupuesto, cuentan con su propia dependencia recaudadora y pagadora, situación que es posible gracias a la descentralización, que “... consiste en confiar la realización de algunas actividades administrativas a órganos que guardan con la administración central una relación diversa de la jerarquía" (Fraga, 1978, p. 220 y 221), lo cual facilita el trámite de los asuntos porque evita la acumulación del poder en el órgano central.

\section{La efectividad de las demás garantías que pueden amparar la calidad en los contratos estatales}

De conformidad con el artículo 5.1.3 del Decreto 734 de 2012, además de la póliza de seguro, el contratista puede constituir cualquiera de las siguientes garantías: 1) fiducia mercantil en garantía, 2) garantía bancaria a primer requerimiento, 3) endoso en garantía de títulos valores, y, 4) depósito de dinero en garantía y cartas de crédito stand by, cuyas características generales se señalan a continuación a fin de demostrar que tampoco es posible a través de ellos lograr el resarcimiento directo por la ejecución imperfecta o defectuosa del objeto contractual atribuible al 
contratista, toda vez que cualesquier suma que determine la entidad contratante como valor del siniestro, debe cumplir el principio de unidad de caja:

- Fiducia mercantil en garantía: para Villagorda, el fideicomiso es el contrato por el cual "... una persona transmite plenamente a otra ciertos bienes 0 derechos, obligándose éste a afectarlos a la realización de una finalidad lícita y determinada $y$, como consecuencia de dicha finalidad, obligándose a retransmitir dichos bienes o derechos a favor de un tercero o revertirlos a favor del transmitente" (1982, p. 55 y 56).

Según Carregal "El contrato de fideicomiso es aquel por el cual una persona recibe de otra un encargo respecto de un bien determinado cuya propiedad se le transfiere a título de confianza, para que el cumplimiento de un plazo o condición le dé el destino convenido" (1982, p. 87).

La fiducia mercantil sirve como garantía porque, a través de este contrato, los bienes cuya propiedad se transmite a la fiduciaria constituyen un patrimonio autónomo, lo cual favorece a la entidad beneficiaria de ella en la medida en que los bienes fideicometidos se sustraen de la prenda general de los otros acreedores del fiduciante, sin embargo, la desventaja de esta garantía es que permite que los bienes fideicometidos sean perseguidos por quienes eran acreedores del fiduciante desde antes de la constitución del fideicomiso, de acuerdo con el artículo 1238 del Código de Comercio (Arrubla, 2005).

Como mecanismo de cobertura del riesgo, esta garantía permite a la entidad solicitar a la fiduciaria la venta de los bienes fideicometidos para que, con su producto, le pague los daños derivados de la ejecución imperfecta o defectuosa del objeto contractual, devolviendo el excedente al contratista. Sin embargo, 
cuando se haga efectivo este mecanismo de cobertura del riesgo, la suma determinada por la entidad deberá cumplir el principio de unidad de caja, y como consecuencia de ello, no podrá ser utilizada directamente por ella, debiendo ser reintegrada al Tesoro Nacional, y si requiere efectuar algún gasto con cargo a esos recursos, el mismo deberá ser presupuestado a través de la Dirección General del Presupuesto Público Nacional; en consecuencia, por esta vía la entidad contratante no puede lograr un resarcimiento directo e inmediato.

- Garantía bancaria a primer requerimiento: la garantía bancaria a primer requerimiento es el contrato por el cual un banco/garante, previa solicitud del ordenante (contratista), asume el compromiso irrevocable de pagar una suma determinada de dinero a un tercero/beneficiario (entidad) con la mera solicitud que éste le haga, adjuntando los documentos que para tal efecto se establezcan y en donde conste la obligación incumplida.

Para la ejecución de la garantía, la entidad deberá efectuar la reclamación por escrito, solicitando el pago al banco que haya garantizado la respectiva obligación de calidad derivada del contrato celebrado, allegando los documentos señalados en el texto de la garantía y dentro de la vigencia de la misma.

Por otra parte, debido a que esta garantía solo se paga en dinero y es intuito personae, los derechos derivados de la misma no son cesibles ni pignorables a favor de un tercero cuando se haga efectiva (León, 2006), así, la suma que se pague a la entidad deberá cumplir el principio de unidad de caja, y como consecuencia de ello, no podrá ser utilizada directamente por ella, debiendo ser reintegrada al Tesoro Nacional, y si requiere efectuar algún gasto con cargo a esos recursos, el mismo deberá ser presupuestado a través de la Dirección General del Presupuesto Público Nacional; en consecuencia, por esta vía no 
solo no se puede lograr un resarcimiento directo e inmediato, sino que tampoco se puede presentar la figura de la reparación en especie.

- Endoso en garantía de títulos valores: los títulos valores son "documentos necesarios para legitimar el ejercicio del derecho literal y autónomo que en ellos se incorpora" (Trujillo, 2005, p. 39; Rengifo, 2008, p. 34; Ruiz, 2003, p. 11), y aunque normalmente pueden consistir en letras de cambio, pagarés, cheques, certificados de depósitos, etc. (Montoya, Montoya \& Montoya, 2004), como garantías contractuales solo son aceptables los certificados de depósito a término emitidos por una entidad financiera sometida a vigilancia y control de la Superintendencia Financiera, los pagarés emitidos por una entidad financiera sometida a vigilancia y control de la Superintendencia Financiera y, los títulos de tesorería (TES). Por su parte, el endoso es el escrito accesorio, inseparable del título, mediante el cual el acreedor cambiario pone en su lugar a otro acreedor (Cabeza, 1936).

Estos documentos son cosas y por ello pueden servir de garantía real a través del endoso en garantía que, a su vez, es el gravamen que se constituye sobre los derechos incorporados en el título valor, mediante la inserción de la cláusula "en garantía", "en prenda", u otra semejante, y aunque no transfiere al endosatario la propiedad del título, sí le confiere los derechos de acreedor prendario y las facultades que da el endoso en procuración.

El endosatario en garantía puede cobrar en nombre propio el título valor, sin que se le puedan proponer las excepciones personales que se le podrían formular al endosante (Leal, 2011), y destinar la suma cobrada para cubrir las obligaciones garantizadas (siempre que éstas no estén satisfechas), debiendo devolver el excedente de lo cobrado. Cabe resaltarse que si al momento del 
cobro del título valor el deudor del contratista endosante no paga, la entidad deberá acudir al proceso ejecutivo.

Así las cosas, cuando se haga efectivo este mecanismo de cobertura del riesgo, la suma determinada por la entidad deberá cumplir el principio de unidad de caja, y como consecuencia de ello, no podrá ser utilizada directamente por ella, debiendo ser consignada al Tesoro Nacional, y si requiere efectuar algún gasto con cargo a esos recursos, el mismo deberá ser presupuestado a través de la Dirección General del Presupuesto Público Nacional; en consecuencia, por esta vía no solo no se puede lograr un resarcimiento directo e inmediato, sino que tampoco es posible concebir, prima facie, la figura de la reparación en especie.

- Depósito de dinero en garantía y cartas de crédito stand by: de conformidad con el artículo 2236 del Código Civil, el depósito es el contrato por el cual se confía una cosa corporal (que puede ser dinero) a una persona que se encarga de guardarla y restituirla en especie. La ejecución de esta garantía contractual consistirá entonces, en la solicitud hecha por la entidad al depositario de que le entregue la suma depositada en garantía hasta por el valor del daño derivado de la ejecución imperfecta o defectuosa del objeto contractual, restituyendo éste el exceso del depósito al contratista.

Por su parte, para la ejecución de la garantía consistente en una carta de crédito stand by (que por sí misma es una garantía personal de cumplimiento), la entidad primero deberá solicitar al contratista el pago del valor por el cual se haya tasado el daño derivado de la ejecución imperfecta o defectuosa del objeto contractual, y en caso de que éste no pague ${ }^{16}$, solicitará el pago al banco que

\footnotetext{
${ }^{16}$ Esta garantía se asemeja a la fianza, por ello el pago debe exigirse primero al deudor.
} 
haya garantizado la respectiva obligación de calidad derivada del contrato celebrado, allegando los documentos señalados en el texto de la garantía.

Pero de llegar a hacerse efectivo alguno de estos mecanismos de cobertura del riesgo, la suma determinada por la entidad deberá cumplir el principio de unidad de caja, y como consecuencia de ello, no podrá ser utilizada directamente por ella, debiendo ser consignada al Tesoro Nacional, y si requiere efectuar algún gasto con cargo a esos recursos, el mismo deberá ser presupuestado a través de la Dirección General del Presupuesto Público Nacional; en consecuencia, por esta vía tampoco se puede lograr un resarcimiento directo e inmediato para la entidad contratante.

Evidentemente, en Colombia las únicas entidades que tienen garantizado su derecho al resarcimiento directo por la ocurrencia de un siniestro contractual son las del nivel descentralizado y las entidades territoriales, quienes no solo tienen autonomía para la administración y disposición de sus recursos sino que, además, cuentan con una dependencia propia para su recaudo; la otra cara de la moneda son las entidades del nivel central y los establecimientos públicos, para quienes este derecho continúa en deuda debido a los vacíos que tiene el régimen de garantías contractuales en relación con este tema y para quienes solo es posible lograr una indemnización directa cuando el valor del siniestro se cancela en especie pues, a nadie se le ocurriría remitir a la DTN un bien que haya sido entregado por el garante a la entidad en ejercicio de la facultad consagrada por el artículo 1110 del Código de Comercio, el cual le permite pagar a través de la reposición, reparación o reconstrucción de la cosa asegurada.

\section{El caso chileno}


En Chile, la situación no dista demasiado del caso colombiano, al revisar los artículos 30, 31, 32 y 35 del Decreto Ley No. 1263 de 1975 (Orgánico de Administración Financiera del Estado), se advierte que la Tesorería de la República es la entidad encargada de recaudar los fondos del sector público (tributos y demás entradas fiscales), para luego distribuirlos con eficiencia. Esta entidad cuenta incluso con facultades para el cobro coactivo (judicial, extrajudicial o administrativo) de los impuestos fiscales en mora (con sus intereses y sanciones), así como para el cobro de las multas aplicadas por autoridades administrativas, los créditos fiscales a los que la ley dé el carácter de impuesto para los efectos de su recaudación, y, los demás créditos de cualquiera naturaleza que tengan causa en el cumplimiento de las obligaciones tributarias cuya cobranza se encomiende al Servicio de Tesorerías. No obstante, en el caso de las municipalidades, éstas pueden adelantar el cobro administrativo y judicial de los ingresos propios que generan de acuerdo con su Ley de Rentas Municipales.

Por otra parte, para garantizar la coordinación y la unidad de la gestión financiera del Estado, el artículo 3 del Decreto Ley No. 1263 de 1975 dispone que el presupuesto, la contabilidad y la administración de fondos se rigen por normas comunes y los ingresos que percibe el Estado se reflejan en el presupuesto del Sector Público, sin perjuicio de mantener su carácter regional, sectorial o institucional, y el Servicio de Tesorería efectúa el recaudo de los ingresos del sector público, salvo los que constituyen entradas propias de los servicios (artículo 4). Así, los ingresos del sector público, salvo los exceptuados por Ley, deben depositarse en la Cuenta Única Fiscal del Banco del Estado, la cual se subdivide en una cuenta principal, mantenida por la Tesorería General de La República, y varias cuentas subsidiarias, destinadas a los servicios. 
No obstante lo anterior, si bien el artículo 11 de la Ley 19.886 de 2003 (ley de contratación) señala que la entidad debe solicitar las garantías necesarias para asegurar el cumplimiento del contrato pudiendo hacer efectivas las multas y demás sanciones que afecten a los contratistas, en relación con el recaudo del valor de las garantías contractuales, el Decreto Ley No. 1263 de 1975 no asigna a la Tesorería de la República funciones específicas de cobro de las mismas, mientras que el artículo 72 del Decreto No. 250 de 2004 (Reglamentario de la Ley 19.886) señala que, en caso de incumplimiento de las obligaciones contractuales por parte del contratista, la entidad está facultada para hacer efectiva la garantía de cumplimiento administrativamente, sin perjuicio de otras acciones para exigir el cumplimiento forzado o la resolución del contrato y la indemnización de perjuicios.

Visto lo anterior, a continuación se presenta un cuadro comparativo de los regímenes chileno y colombiano:

\section{SEMEJANZAS}

- En ambos regímenes la entidad debe solicitar las garantías necesarias para asegurar el cumplimiento del contrato.

- En ambos regímenes se pueden hacer efectivas las multas y demás sanciones que afecten a los contratistas.

- En caso de incumplimiento de las obligaciones contractuales por parte del contratista, en ambos regímenes la entidad puede hacer efectiva la garantía de cumplimiento administrativamente sin perjuicio de otras acciones para exigir el cumplimiento forzado o la resolución del contrato y la indemnización de perjuicios.

- En ambos regímenes hay una entidad encargada de recaudar los fondos del sector público para luego distribuirlos con eficiencia, en el caso chileno es la 
Tesorería de la República y en el caso colombiano es la DTN; en ambos casos, los ingresos que percibe el Estado se reflejan en el presupuesto general, por lo cual, es difícil el logro de un resarcimiento directo cuando se hacen efectivas las garantías derivadas de la calidad del objeto contractual.

\section{DIFERENCIAS}

En Colombia la facultad para el cobro de las multas aplicadas por las autoridades administrativas la tiene la entidad contratante, quien debe reintegrarlas a la DTN, mientras que en Chile la Tesorería de la República tiene facultades para el cobro judicial, extrajudicial o administrativo de las multas aplicadas por autoridades administrativas, salvo el caso de las municipalidades, que pueden adelantar el cobro administrativo y judicial de los ingresos propios.

\section{Discusión: una solución legislativa}

En materia de garantías, la armonía entre las normas económicas y las contractuales no se ha logrado, tal como se evidencia al momento de interpretar y articular estos regímenes, por ello, debe haber un esfuerzo legislativo capaz de generar un cambio que permita a las entidades del nivel central y a los establecimientos públicos contar con garantías eficientes, que les faciliten lograr un resarcimiento directo cuando, por culpa del contratista, se vean afectadas por la ejecución imperfecta o defectuosa del objeto contractual; es cierto que los recursos públicos son escasos y que el principio de unidad de caja tiene la noble finalidad de priorizar las necesidades públicas para atenderlas en forma racional y oportuna, pero el retorno de las indemnizaciones a las entidades que han hecho efectivas las garantías debe ser una realidad acorde con los principios de planeación, eficacia, eficiencia y economía, de lo contrario, los fines del Estado y todas las necesidades sociales o institucionales que se garantizan a través de los contratos administrativos no podrán satisfacerse a cabalidad. 
El derecho de obligaciones indica que los sujetos de la obligación son los que están vinculados en cuanto a su identidad, tanto quien paga como quien recibe, pero, cuando el pago se consigna a favor de la DTN, no se satisface este requisito, por lo tanto, la entidad que debería recibir el pago del siniestro es la que lo impuso dado el vínculo jurídico existente entre ella y el contratista y su garante, solo así se cumpliría el principio de relatividad, por el cual, todo contrato obliga solo a las partes contratantes (artículo 1602 del Código Civil), y a pesar de que una de las excepciones a este principio la constituye el contrato de seguros (típico caso de la estipulación para otro), si la beneficiaria del vínculo entre el contratista y su garante es la entidad contratante, lo justo sería aceptar que todo pago derivado de la ejecución de las garantías le sea entregado directamente a ella.

Evidentemente, la solución del problema solo puede ser legislativa toda vez que el carácter orgánico del Estatuto del Presupuesto la hace una norma jerárquicamente superior al E.G.C.A.P., en consecuencia, resulta necesaria la modificación de la norma presupuestal a fin de que el legislador autorice expresamente no solo la posibilidad de que el pago del valor del siniestro se pueda realizar en dinero o en especie, estableciendo un procedimiento eficiente para ello, sino también que, en caso de que el pago se efectúe en dinero por parte del contratista o de su garante, éste ingrese a los fondos internos de la entidad y con destinación específica a la reparación del perjuicio causado, preferiblemente mediante un proceso de contratación expedito para que la satisfacción de la necesidad que motivó la celebración del contrato estatal se atienda sin mayores dilaciones.

\section{Conclusiones}


El procedimiento para hacer efectivas las garantías por la ejecución imperfecta o defectuosa del objeto contractual es un trámite desgastante que no permite el resarcimiento directo e inmediato de las entidades del nivel central ni de los establecimientos públicos que lo adelantan porque, debido a un vacío normativo del régimen de contratación, cuando el garante paga la indemnización en dinero, ésta debe ingresar al Tesoro Nacional en virtud del principio de unidad de caja consagrado en el Estatuto Orgánico del Presupuesto, lo cual perjudica a estas entidades y resulta contrario a los principios constitucionales y legales que orientan la contratación estatal, principalmente, el de economía, pues, al final la Administración quedará con un daño sin indemnización, lo cual, lamentablemente conlleva a la conclusión de que las garantías contractuales no están real y efectivamente encaminadas a lograr que el contratista cumpla sus obligaciones evitando con ello la paralización del contrato, su afectación grave o su incumplimiento. En tal virtud, puede afirmarse que solo cuando el asegurador asume la posición de contratista a través de la reposición, reparación o reconstrucción de la cosa asegurada, resulta posible hablar de un resarcimiento directo que permite cumplir los fines perseguidos con la celebración del contrato.

La consignación del valor del siniestro a la DTN no solo lesiona los intereses de la entidad perjudicada con la ejecución imperfecta o defectuosa del objeto contractual, sino que subordina su derecho al resarcimiento a que la Dirección General del Presupuesto Público Nacional le asigne nuevos recursos con el fin adelantar un proceso de contratación para la reparación del daño causado, lo cual contradice los principios que inspiran los seguros de responsabilidad civil, en donde la víctima tiene derecho a ser indemnizada en forma directa como sujeto del daño patrimonial y como beneficiaria del contrato de seguro, situación que no solo resulta desgastante para las entidades sino que también resulta contraria a los principios que orientan la función pública y la contratación administrativa. 
Al amparo del artículo 70 del Decreto 222 de 1983 la garantía única hacía parte integrante del contrato garantizado pero, con la entrada en vigencia de la Ley 80, esta figura quedó debilitada y se hace necesario recuperarla y fortalecerla para dotar a las entidades contratantes de mecanismos que realmente les permitan lograr una reparación efectiva cuando los contratistas no cumplan a cabalidad con sus obligaciones y así satisfacer la necesidad que motivó la celebración del contrato estatal y que consulta el interés general, por tal razón, la solución de este problema está en manos del Congreso de la República, a través de sendas reformas al Estatuto Orgánico del Presupuesto y al E.G.C.A.P.

El vacío legislativo del régimen de garantías en relación con el pago de los siniestros declarados por las entidades estatales resulta ilógico porque la Ley 80 (artículo 4, ordinales $1^{\circ}$ y 29 establece que, para la consecución de los fines perseguidos a través de la celebración de los contratos, las entidades estatales no solo pueden exigir del contratista y su garante la ejecución idónea y oportuna del objeto contratado, sino que deben adelantar las gestiones necesarias para el reconocimiento y cobro de las sanciones pecuniarias y garantías a que hubiere lugar, derechos que están incompletos si su ejercicio no conlleva al logro del objetivo para el cual se establecieron. En otras palabras, una garantía que no posibilita la reparación directa e inmediata del siniestro acaecido, resulta ineficiente e insuficiente frente al fin para cual se estipuló dentro de un contrato administrativo.

La legislación colombiana en materia de mecanismos de cobertura del riesgo debería ser conforme a la lógica del derecho de daños y a la teoría general de las obligaciones, solo así brillaría la seguridad jurídica y se garantizaría el derecho al resarcimiento cuando quiera que las entidades estatales se vieran lesionadas en 
su patrimonio por la deficiente ejecución un objeto contractual, máxime si se considera que la Administración tiene una actividad reglada que se debe allanar al postulado consagrado en el artículo 1 de la Ley 489 de 1998 por virtud del cual, la finalidad de la función administrativa es la satisfacción de las necesidades generales de todos los habitantes y su ejercicio debe estar inspirado en el interés general.

Solo se puede pretender la reparación del daño propio y para que ese daño sea resarcible debe ser cierto, directo, personal y debe lesionar un interés legítimo, en consecuencia, si la DTN no es persona jurídica, no es parte del contrato estatal, no es ni asegurada ni beneficiaria del contrato de seguro y tampoco es la víctima directa del daño causado por el contratista, la conclusión lógica sería que de ninguna manera tiene derecho o legitimación alguna para recibir el pago efectuado por el contratista o por su garante con ocasión de la declaratoria de un siniestro contractual; ello se hace especialmente evidente cuando el valor del siniestro se cancela en especie por parte del garante en ejercicio de la facultad consagrada por el artículo 1110 del Código de Comercio, que le permite pagar a través de la reposición, reparación o reconstrucción de la cosa asegurada, en donde resulta difícil entender cómo debería darse cumplimiento al principio de unidad de caja respecto de una obra reparada por el asegurador y, se advierte la falta de lógica legislativa en la articulación de los regímenes presupuestal, contractual y de garantías, en donde es fehaciente la falta de integración sistemática de las normas y por ello se presentan problemas prácticos en la ejecución de las garantías.

La garantía única, que debería tener una función reparadora, en la práctica ha adquirido una función más preventiva y por ello su principal aporte en la actividad contractual está asociado a que solo sirve como mecanismo de presión al contratista para la solución de los conflictos derivados de la ejecución contractual, 
los cuales pueden solucionarse a través del arreglo directo y de los mecanismos alternativos de solución de conflictos. Esta situación se presenta porque el artículo 90 del Estatuto Anticorrupción ha consagrado una inhabilidad para contratar derivada del incumplimiento reiterado del contratista, lo cual, a pesar de brindar a la entidad una herramienta adicional de negociación, desdibuja la finalidad indemnizatoria de la garantía.

A pesar de que en el régimen de garantías contractuales se han consagrado cuatro mecanismos de cobertura del riesgo diferentes de la póliza de seguro, a través de ellos tampoco es posible el logro de un resarcimiento directo e inmediato de los daños causados a la entidad por la ejecución imperfecta o defectuosa del objeto contractual atribuible al contratista, debido a que los pagos efectuados con ocasión de los siniestro declarados con cargo a dichas garantías, debe cumplir con el principio de unidad de caja. No obstante, sea cual sea la garantía constituida por el contratista, en el caso de las entidades del nivel descentralizado y de las entidades territoriales sí es posible la efectividad del derecho al resarcimiento por la declaratoria de un siniestro contractual atribuible al contratista debido a que, además de la Hacienda Nacional, hay una hacienda pública en los órdenes departamental, distrital y municipal, que a pesar de regirse por principios y normas comunes, facilitan que dichas entidades tengan plena autonomía para el recaudo, administración y disposición de sus haberes.

\section{Referencias}

Ariño, G. (2003). Principios de derecho público económico. Bogotá, Colombia: Ediciones Universidad Externado de Colombia.

Arrubla, J. A. (2005). Contratos mercantiles, Tomo III. Medellín, Colombia: Biblioteca Jurídica Diké. 
Bustamante, J. (1993). Teoría general de la responsabilidad civil (8ª Ed.). Buenos Aires, Argentna: Abeledo-Perrot.

Caballero, E. (1992). La prevención y el seguro. En Fasecolda (Ed.), Ensayos sobre seguros, homenaje al doctor J. Efrén Ossa G. (pp. 47-57). Santafé de Bogotá, Colombia: Editor.

Campillo, C. (2006). Celebración y ejecución de contratos estatales (2 $2^{\mathrm{a}}$ Ed.). Bogotá, Colombia: Ecoe Ediciones.

Carregal, M. (1982). El fideicomiso, regulación jurídica y posibilidades prácticas. Buenos Aires, Argentina: Editorial Universidad.

Colombia, Asamblea Nacional Constituyente. (1991). Constitución Política de Colombia. Bogotá, Colombia: Autor.

Colombia, Congreso de la República. (1873). Código Civil. Bogotá, Colombia: Autor.

Colombia, Congreso de la República. (2012). Código de Procedimiento Administrativo y de lo Contencioso Administrativo. Bogotá, Colombia: Autor.

Colombia, Congreso de la República. (1993). Ley 42. Bogotá, Colombia: Autor.

Colombia, Congreso de la República. (1993). Ley 80. Bogotá, Colombia: Autor.

Colombia, Congreso de la República. (1998). Ley 489. Bogotá, Colombia: Autor.

Colombia, Congreso de la República. (2007). Ley 1150. Bogotá, Colombia: Autor.

Colombia, Congreso de la República. (2012). Ley 1474. Bogotá, Colombia: Autor. 
Colombia, Consejo de Estado, Sala de Consulta y Servicio Civil. (2007). Concepto del 15 de noviembre, No. Interno 1.852. Bogotá, Colombia: Autor.

Colombia, Consejo de Estado, Sección Tercera. (2008). Sentencia del 23 de abril, Exp. 16.491. Bogotá, Colombia: Autor.

Colombia, Corte Constitucional. (1992). Sentencia No. C-478. Bogotá, Colombia: Autor.

Colombia, Corte Constitucional. (1993). Sentencia C-337. Bogotá, Colombia: Autor.

Colombia, Corte Constitucional. (1996). Sentencia C-154. Bogotá, Colombia: Autor.

Colombia, Corte Constitucional. (2002). Sentencia C-648. Bogotá, Colombia: Autor.

Colombia, Presidencia de la República. (1971). Código de Comercio. Bogotá, Colombia: Autor.

Colombia, Presidencia de la República. (1983). Decreto Ley No. 222. Bogotá, Colombia: Autor.

Colombia, Presidencia de la República. (1996). Decreto No. 111. Bogotá, Colombia: Autor.

Colombia, Presidencia de la República. (2012). Decreto reglamentario No. 734. Bogotá, Colombia: Autor. 
Chartered Insurance Institute de Londres. (1979). Aspectos legales y económicos del seguro (2 ${ }^{\underline{a}}$ Ed.). Madrid, España: Mapfre.

Chile, Congreso Nacional. (2003). Ley 19.886. Valparaíso, Chile: Autor.

Chile, Presidencia de la República. (2004). Decreto No. 250. Santiago, Chile: Autor.

Chile, Presidencia de la República. (1975). Decreto Ley No. 1263. Santiago, Chile: Autor.

Díaz, A. (2009). El fraude y su incidencia en el contrato de seguro. Bogotá, Colombia: Grupo Editorial Ibáñez.

Escobar, R. (1993). Teoría general de los contratos de la administración pública. Santafé de Bogotá, Colombia: Legis.

Escobar, R. (2003). Teoría general de los contratos de la administración pública. Santafé de Bogotá, Colombia: Legis.

Estigarribia, M. L. (2011). La buena fe. Implicaciones contractuales en las relaciones negociales. En J. Oviedo (Comp.), Contratos teoría general, principios y tendencias (2ª Ed.). (pp. 173-198). Bogotá, Colombia: Grupo Editorial lbáñez.

Expósito, J. C. (2008). La mora en las obligaciones de hacer en la contratación estatal. En Universidad Externado de Colombia (Ed.), Libro homenaje al profesor Luis Villar Borda. (p. 500). Bogotá, Colombia: Editor.

Fraga, G. (1978). Derecho administrativo (18 $8^{\mathrm{a}}$ Ed.). México, México: Porrúa. 
García, E. \& Fernández, T. (1993). Curso de derecho administrativo (4ª Ed.). Madrid, España: Civitas.

Giraldo, A. (2010). Derecho administrativo general (8ª Ed.). Medellín, Colombia: Señal Editora.

Güechá, C. (2010). Contratos administrativos control de legalidad en el procedimiento administrativo de contratación. Bogotá, Colombia: Grupo Editorial Ibáñez.

Hemard, J. (1925). Teoría y práctica de los seguros terrestres, Tomo II. París, Francia: Sirey.

Henao, J. C. (1998). El daño. Bogotá, Colombia: Ediciones Universidad Externado de Colombia.

Herrera, A. (2006). Aspectos generales del derecho administrativo colombiano ( $2^{\mathrm{a}}$ Ed.). Barranquilla, Colombia: Ediciones Uninorte.

Higuita, L. M. (2006). Guía práctica de la administración pública. Medellín, Colombia: Biblioteca Jurídica Diké.

Hinestrosa, F. (2003). Tratado de las obligaciones, Tomo I (2 $2^{\mathrm{a}}$ Ed.). Bogotá, Colombia: Ediciones Universidad Externado de Colombia.

Instituto de Investigaciones Jurídicas. (1998). Diccionario jurídico mexicano, Tomo I/ (11를. Ed. México, México: Porrúa.

Isaza, M. C. (2009) De la cuantificación del daño manual teórico - práctico. Bogotá, Colombia: Temis. 
Josserand, L. (1984). Derecho civil (3를. Ed.). Buenos Aires, Argentina: Ediciones Jurídicas Europa - América.

Leal, H. (2011). Títulos valores (13를 Ed.). Bogotá, Colombia: Leyer.

León, C. (2006). Aplicabilidad de las garantías bancarias a primer requerimiento en el ordenamiento jurídico colombiano. Revista de derecho privado, 10, 103-121.

Mantilla, F. \& Ternera, F. (2007). Los contratos en el derecho privado. Bogotá, Colombia: Legis.

Mazeaud, H., Mazeaud, L. \& Tunc, A. (1977). Tratado teórico y práctico de la responsabilidad civil delictual y contractual, Tomo I, Vol. I (5aㅡ. Ed.). Buenos Aires, Argentina: Ediciones Jurídicas Europa - América.

Messineo, F. (2007). Doctrina general del contrato (3ª Ed.). Lima, Perú: Ara Editores.

Montoya, U., Montoya, U. \& Montoya, H. (2004). Derecho comercial, Tomo I (11 Ed.). Lima, Perú: Editora Jurídica Grijley.

Montoya, U., Montoya, U. \& Montoya, H. (2004). Derecho comercial, Tomo II (11 Ed.). Lima, Perú: Editora Jurídica Grijley.

Morales, D. (2009). La gestión del presupuesto público colombiano. Pereira, Colombia: Editorial Papiro.

Naranjo, V, (1997). Teoría constitucional e instituciones políticas (7ª̣ Ed.). Bogotá, Colombia: Temis. 
Ocampo, H. (2008). Coquito recargado: ejercicios didácticos para entender los presupuestos públicos ( $3^{\mathrm{a}}$ Ed.). Bogotá, Colombia: Ministerio de Hacienda y Crédito Público.

Oliveros, A. (2012). La causalidad en el derecho de daños. Medellín, Colombia: Librería Jurídica Sánchez R.

Orgaz, A. (1960). El daño resarcible (2 $2^{\mathrm{a}}$ Ed.). Buenos Aires, Argentina: Bibliográfica Omeba.

Parra, W. (2003). Responsabilidad patrimonial estatal daño antijurídico. Bogotá, Colombia: Pretextos Grupo Editorial.

Rengifo, R. (2008). Títulos valores (12ª Ed.). Medellín, Colombia: Librería Señal Editora.

Rivera, J. C. (1997). Instituciones de derecho civil, parte general, Tomo I. Buenos Aires, Argentina: Abeledo Perrot.

Ruiz, J. (2003). Manual de títulos valores. Bogotá, Colombia: Ediciones Doctrina y Ley.

Salguero, G. (1983). Contratos administrativos (3 $3^{\mathrm{a}}$ Ed.). Bogotá, Colombia: Ediciones Librería del Profesional.

Solano, J. (2010). Contratación administrativa (4⿳亠丷厂 Ed.). Bogotá, Colombia: Ediciones Doctrina y Ley.

Solarte, A. (2011). La buena fe contractual y los deberes secundarios de conducta. En J. Oviedo (Comp.), Contratos teoría general, principios y tendencias ( $2^{\underline{a}}$ Ed.). (pp. 93-126). Bogotá, Colombia: Grupo Editorial Ibáñez. 
Stiglitz, R. (1998). Contratos civiles y comerciales, parte general, Tomo I. Buenos Aires, Argentina: Abeledo Perrot.

Stiglitz, R. (2010). Temas de derecho de seguros. Bogotá, Colombia: Grupo Editorial Ibañez.

Traviesas, M. (1934). Sobre contrato de seguro terrestre. Madrid, España: Editorial Revista de Derecho Privado.

Trujillo, B. (2005). De los títulos valores, Tomo I, Parte General (14를.). Bogotá, Colombia: Leyer.

Uribe, R. (1982). De las obligaciones y de los contratos en general. Bogotá, Colombia: Temis.

Valencia, A. \& Ortiz, A. (2002). Derecho civil, Tomo III, De las obligaciones (10aㅡ Ed.). Bogotá, Colombia: Temis.

Vedel, J. (1980). Derecho administrativo. Madrid, España: Biblioteca Jurídica Aguilar.

Villagorda, J. M. (1982). Doctrina general del fideicomiso. México, México: Porrúa.

Villar, L., Hernández, A., Valencia, F., Cotrino, O., Pino, J. \& Atehortúa, C. (2000). Régimen de las entidades territoriales, Tomo I. Bogotá, Colombia: Ediciones Universidad Externado de Colombia.

Vivante, C. (1936). Tratado de derecho mercantil, Tomo III. Madrid, España: Reus. 